\title{
The shortage of medical oncologists: the Australian Medical Oncologist Workforce Study
}

\section{Prunella L Blinman BMed, FRACP, Medical Oncologist ${ }^{i}$ \\ Peter Grimison} MPH, PhD, FRACP, Medical Oncologist ${ }^{2}$

Michael B Barton OAM, MD, FRANZCR, Professor of Radiation Oncology ${ }^{3}$

Sally Crossing AM, BEc,
Chair $^{4}$

Euan T Walpole MB BS, FRACP. Medical Director

Nora Wong BCom/BSocSc, Project Officer, Special Projects ${ }^{6}$

Kay Francis BA(Hons), MA(Hons), MBA, Executive Officer

Bogda Koczwara MB BS, FRACP, MBioethics Head

1 Medical Oncology, Concord Repatriation General Hospital, Sydney, NSW.

2 Medical Oncology, Sydney Cancer Centre, Sydney, NSW.

3 Faculty of Medicine, University of New South Wales, Sydney, NSW.

4 Cancer Voices NSW. Sydney, NSW.

5 Cancer Services, Princess Alexandra Hospital, Brisbane, QLD.

6 Medical Oncology Group of Australia Sydney, NSW.

7 Medical Oncology, Flinders Medical Centre Flinders University, Adelaide, SA.

prunella.blinman@ sswahs.nsw.gov.au

MJA 2012; 196: 58-61 doi: 10.5694/mjall.10363

Perspective p 32 oncerns are increasing in Australia and internationally that the supply of medical oncologists (MOs) is insufficient to meet the rising demand. ${ }^{1-5}$ The only study of the medical and haematological oncology workforce in Australia was published in 2001. ${ }^{6}$ This study found that there were $180 \mathrm{MOs}$ in active practice in Australia (0.9 per 100000 population), and an estimated shortfall of at least 40 medical and haematological oncologists.

The best estimate of the number of MOs in Australia in 2009 was 311, based on the membership of the Medical Oncology Group of Australia (MOGA), the peak representative body for MOs in Australia. This equates to $1.4 \mathrm{MOs}$ per $100000 \mathrm{popu}-$ lation. Despite the increase since 2001, this figure is still well below comparable international figures, such as the 3.5 MOs per 100000 population reported in the United States in $2005 .^{7}$

In response to consumer concerns about the medical oncology workforce shortage, the Australian Medical Oncologist Workforce Study was initiated by MOGA in 2009. The purpose of this cross-sectional study was to evaluate the current and future capacity of the MO workforce by estimating the supply, demand and shortfall of MOs in Australia in 2009 and 2014.

\section{Methods}

\section{Study population}

Lead clinicians, directors, or solo practitioners ("lead clinicians") of all public and private adult medical oncology practices in Australia were invited to complete a self-administered survey. Lead clinicians could represent more than one practice. Practices and lead clinicians were identified using the MOGA membership database, consumer directories and databases of state and federal departments of health. Institutional human research ethics committee

\begin{abstract}
Objective: To determine current and projected supply, demand and shortfall of medical oncologists (MOs) and the Australian chemotherapy utilisation rate.
\end{abstract}

Design, setting and participants: A 2009 cross-sectional observational study of Australian adult medical oncology practice work patterns.

Instrument: Electronic or paper self-administered questionnaire.

Main outcome measures: The 2009 and projected (2014) supply, demand and shortfall of full-time equivalent (FTE) MOs, and the chemotherapy utilisation rate.

Results: 476 medical oncology positions comprising 234 FTE MOs were identified. Of the 150 medical oncology practices, 117 (78\%) were in metropolitan locations and 33 (22\%) were in rural locations. The average number of new patients seen per FTE MO was 270 patients (ranging by state from 191 to 343). The demand for FTE MOs was estimated at 326 to 391 in 2009 and 361 to 432 in 2014. The shortfall of FTE MOs was estimated at 92 to 157 in 2009 and 84 to 156 in 2014. The chemotherapy utilisation rate was 19\%.

Conclusions: The current shortage of $\mathrm{MOs}$ is expected to persist in the future. National strategies are needed to increase the capacity of the medical oncology workforce and the chemotherapy utilisation rate.

approval of the study was obtained from the University of Wollongong.

\section{The survey}

A 23-item study-specific survey sought the following information from lead clinicians about their practice in 2008:

- nature of the practice (public, private or other; metropolitan or rural)

- current workforce (number and sex of MOs; full-time equivalent [FTE] MOs [filled and unfilled positions]; additional clinical appointments)

- workload (new patients; new patients who received chemotherapy; new chemotherapy courses)

- future supply of MOs (advanced training positions; overseas-trained physicians [OTPs]; MOs expected to retire between 2009 and 2014).

The number of FTE MOs describes the number of full-time equivalent staff members each working 40 hours per week. We distinguished chemotherapy agents from other anticancer agents according to the SEER ${ }^{*} \mathrm{Rx}$ Interactive Antineoplastic Drug Database. "Rural" included all non-metropolitan locations by the rural, remote and metropolitan areas classification. ${ }^{9}$

The survey was developed with the MOGA workforce study working group, following a comprehensive literature review, and could be completed on paper or as an online questionnaire. The survey was administered in July and August 2009. Lead clinicians were initially sent a letter of invitation to participate by post and by email, a participant information sheet, the paper survey, a hyperlink to the online survey and one reminder by email. Non-responding lead clinicians were contacted by telephone and sent two reminders by email as required.

\section{Additional sources of data}

Data were obtained from the Royal Australasian College of Physicians (RACP) about the numbers of medical oncology advanced trainees registered with the RACP and trainees awarded fellowship between 2005 and 2009 . The number of new cases of cancer reported in Australia in 2008 was obtained from state and territory cancer registries. ${ }^{10}$ The projected number of new cases of cancer in Australia during 2014 assumed a growth of $2 \%$ per year. ${ }^{10}$ The populations of each state and territory in June 2009 were obtained from the Australian Bureau of Statistics. ${ }^{11}$ An optimal chemotherapy utilisation rate of $51 \%$ was based 


\begin{tabular}{|c|c|c|c|c|c|c|c|c|c|}
\hline & NSW & VIC & QLD & WA & SA & TAS & ACT & NT & National \\
\hline Practices (\% of national) & $42(28 \%)$ & $56(37 \%)$ & $25(17 \%)$ & $11(7 \%)$ & $5(3 \%)$ & $5(3 \%)$ & $5(3 \%)$ & $1(1 \%)$ & 150 \\
\hline \multicolumn{10}{|l|}{ Type of practice (\% of practices) } \\
\hline Public & $25(60 \%)$ & 22 (39\%) & $10(40 \%)$ & $8(73 \%)$ & $2(40 \%)$ & $3(60 \%)$ & $2(40 \%)$ & $1(100 \%)$ & $73(49 \%)$ \\
\hline Private & $12(29 \%)$ & $27(48 \%)$ & $14(56 \%)$ & $3(27 \%)$ & $3(60 \%)$ & $1(20 \%)$ & $3(60 \%)$ & 0 & $63(42 \%)$ \\
\hline Other & $5(12 \%)$ & $7(17 \%)$ & $1(4 \%)$ & 0 & 0 & $1(20 \%)$ & 0 & 0 & $14(10 \%)$ \\
\hline \multicolumn{10}{|l|}{ Place of practice (\% of practices) } \\
\hline Metropolitan & $28(67 \%)$ & $48(86 \%)$ & $21(84 \%)$ & $6(55 \%)$ & $5(100 \%)$ & $3(60 \%)$ & $5(100 \%)$ & $1(100 \%)$ & $117(78 \%)$ \\
\hline Rural & $14(33 \%)$ & $8(14 \%)$ & $4(16 \%)$ & $5(46 \%)$ & 0 & $2(40 \%)$ & 0 & 0 & $33(22 \%)$ \\
\hline Solo practitioners (\% of practices) & $6(12 \%)$ & $5(9 \%)$ & $4(16 \%)$ & $1(9 \%)$ & $1(20 \%)$ & $3(60 \%)$ & 0 & $1(100 \%)$ & $21(14 \%)$ \\
\hline MOs (\% of national) & $138(29 \%)$ & $176(37 \%)$ & $63(13 \%)$ & $41(9 \%)$ & $28(6 \%)$ & $11(2 \%)$ & $18(4 \%)$ & $1(0.2 \%)$ & 476 \\
\hline MOs attending rural clinics (\% of MOs) & $23(17 \%)$ & $13(7 \%)$ & $10(16 \%)$ & $7(17 \%)$ & $2(7 \%)$ & $2(18 \%)$ & $8(44 \%)$ & 0 & $65(14 \%)$ \\
\hline
\end{tabular}

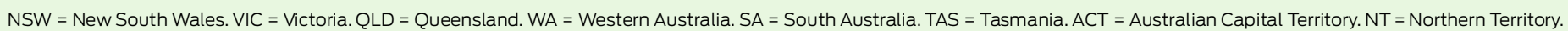
$\mathrm{MO}=$ medical oncologist.

on previous modelling. ${ }^{12}$ Optimal workloads of 150 and 180 new patients seen per FTE MO per year were based on Canadian and Australian benchmarks. ${ }^{1,13}$

\section{Statistical analysis}

Descriptive statistics were used to summarise the responses to the survey at state, territory and national levels. Calculations excluded practices that reported missing data for the relevant item. The chemotherapy utilisation rate was calculated as the ratio of the number of new patients reported in the survey to be receiving chemotherapy, and the new cases of cancer reported to state and territory cancer registries.

The current MO supply was calculated as total FTE MOs for 2009. The projected supply was calculated as current supply + (average number registered advanced trainees/year [an anticipated FTE/qualified specialist of 0.5] $\times 5$ years) - (FTE number expected to retire in the next 5 years).

The demand for FTE MOs was calculated as new cases of cancer reported to cancer registries $\times$ optimal chemotherapy utilisation rate $\div$ benchmarks of 150 and 180 new patients seen/FTE $\mathrm{MO} /$ year. The shortfall was calculated as supply - demand.

Statistical analysis was performed using Microsoft Office Excel 97-2003 (Microsoft, Redmond, Wash, USA).

\section{Results}

\section{Response rate}

We identified 116 eligible lead clinicians in 150 Australian adult medical oncology practices. Ninety-four clinicians completed the survey, eight declined to participate and 14 did not respond (response rate, $81 \%$ ). Data were provided about the number of medical oncology positions in 102 of 150 centres $(68 \%)$, and the number of FTE MOs in 77 of 150 centres (51\%).

We estimated that missing data represented no more than $20(<10 \%)$ unreported FTE MOs because missing data predominantly related to small rural and/or private practices without a dedicated oncologist, three medium metropolitan practices and one regional practice. Data were provided about the number of new patients with cancer seen in 63/150 centres (42\%) (representing 181/234 [77\%] reported FTE MOs), and about the number of new patients who received at least one course of chemotherapy seen in 50/150 (33\%) centres (representing 137/234 [59\%] reported FTE MOs). From these data, we estimated

\section{Medical oncology positions in Australia in 2008}

\begin{tabular}{|c|c|c|c|c|c|c|c|c|c|}
\hline & NSW & VIC & QLD & WA & SA & TAS & ACT & NT & National \\
\hline Population* & 7099700 & 5427800 & 4406800 & 2236900 & 1622700 & 502600 & 351200 & 224800 & 21874900 \\
\hline MOs (\% of national) & $138(29 \%)$ & $176(37 \%)$ & $63(13 \%)$ & $41(9 \%)$ & $28(6 \%)$ & $11(2 \%)$ & $18(4 \%)$ & $1(0.2 \%)$ & $476(100 \%)$ \\
\hline \multicolumn{10}{|l|}{ FTE MOs } \\
\hline FTE MOs filled (\% of national) & $88(35 \%)$ & $68(29 \%)$ & $29(12 \%)$ & $22(9 \%)$ & $20(9 \%)$ & $6(3 \%)$ & $7(3 \%)$ & $1(0.4 \%)$ & $234(100 \%)$ \\
\hline FTE MOs unfilled (\% of national) & $7.5(26 \%)$ & $8.0(28 \%)$ & $6.3(22 \%)$ & 0 & $3.6(13 \%)$ & $2.0(7 \%)$ & $1.1(4 \%)$ & 0 & $29(100 \%)$ \\
\hline Total FTE MOs (\% of national) & $89(34 \%)$ & $76(29 \%)$ & $35(14 \%)$ & $22(8 \%)$ & $24(9 \%)$ & $8(3 \%)$ & $8(3 \%)$ & $1(0.4 \%)$ & $263(100 \%)$ \\
\hline Average FTE per MO & 0.6 & 0.4 & 0.5 & 0.5 & 0.7 & 0.5 & 0.4 & 1 & 0.5 \\
\hline FTE MOs per 100000 population & 1.2 & 1.3 & 0.8 & 1.0 & 1.5 & 1.2 & 1.9 & 0.4 & 1.1 \\
\hline Female MOs (\% of MO) & $46(33 \%)$ & 49 (28\%) & $20(32 \%)$ & $9(22 \%)$ & $9(32 \%)$ & $3(27 \%)$ & $4(22 \%)$ & 0 & $140(29 \%)$ \\
\hline \multicolumn{10}{|l|}{ MOs by practice type (\% of MOs) } \\
\hline Public & $73(53 \%)$ & $90(51 \%)$ & $38(60 \%)$ & $21(51 \%)$ & $13(46 \%)$ & $9(82 \%)$ & $10(56 \%)$ & $1(100 \%)$ & 255 (54\%) \\
\hline Private & $50(36 \%)$ & $85(49 \%)$ & $24(38 \%)$ & $20(49 \%)$ & $15(53 \%)$ & $2(18 \%)$ & $8(44 \%)$ & 0 & $204(43 \%)$ \\
\hline Other & $15(11 \%)$ & $1(0.6 \%)$ & $1(2 \%)$ & 0 & 0 & 0 & 0 & 0 & $17(4 \%)$ \\
\hline \multicolumn{10}{|l|}{ MOs by practice place (\% of MOs) } \\
\hline Metropolitan & $131(95 \%)$ & $172(98 \%)$ & $58(92 \%)$ & $30(73 \%)$ & $28(100 \%)$ & $11(100 \%)$ & $18(100 \%)$ & $1(100 \%)$ & 449 (94\%) \\
\hline Rural & $7(5 \%)$ & $4(2 \%)$ & $5(8 \%)$ & $11(27 \%)$ & 0 & 0 & 0 & 0 & $27(6 \%)$ \\
\hline
\end{tabular}

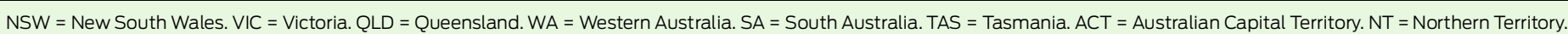
$\mathrm{MO}=$ medical oncologist. FTE = full-time equivalent. * At 30 June 2009. 
that an additional $25 \%$ of new patients with cancer were seen and an additional $40 \%$ of unreported new patients received at least one course of chemotherapy.

\section{Nature of the practices}

Most practices surveyed were in metropolitan areas, a minority were private practices and there were few solo practitioners. Sixty-five MOs $(14 \%)$ attended rural outreach clinics (Box 1).

\section{Current supply}

Of 476 medical oncology positions, 49\% comprised FTE MOs (Box 2). Three-quarters of the FTE MOs were found in the three most populous states or territories (New South Wales, Victoria and Queensland). The national average FTE per medi-

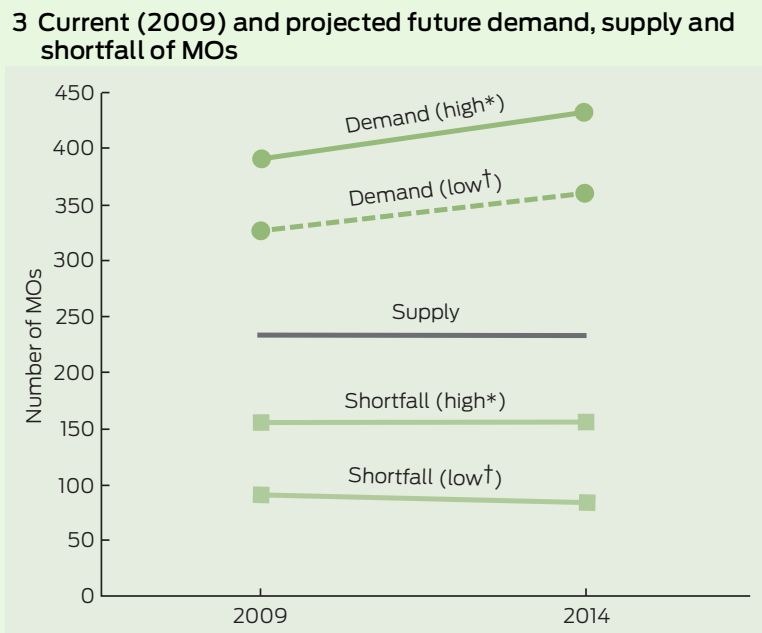

$\mathrm{MO}=$ medical oncologist. *Workload benchmark 150 new patients/MO/ year. $†$ Workload benchmark 180 new patients/MO/year.

\section{Current (2009) supply and shortfall of MOs, by state and} territory

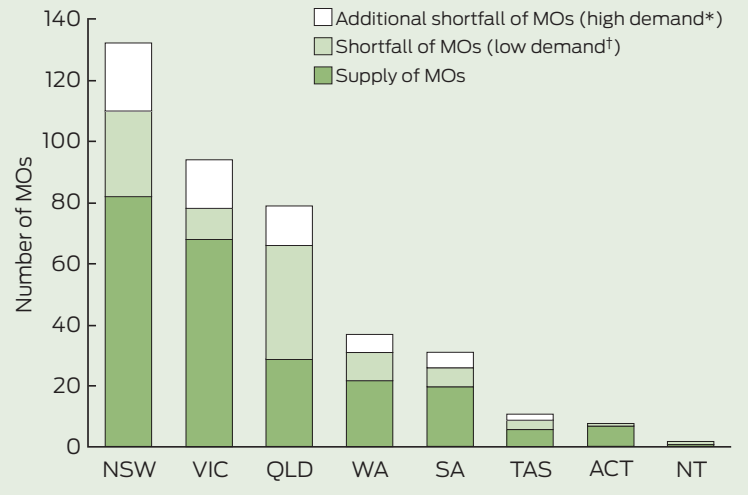

*150 new patients/MO/year. $\dagger 180$ new patients/MO/year. $\mathrm{MO}=$ medical oncologist. NSW $=$ New South Wales. VIC $=$ Victoria. $\mathrm{QLD}=$ Queensland WA = Western Australia. SA = South Australia. TAS = Tasmania. ACT = Australian Capital Territory. NT = Northern Territory. cal oncology position was 0.5 , and almost one-third of the medical oncology positions (29\%) were filled by women. There were more medical oncology positions in public than private practices. Few medical oncology positions were located in rural centres.

\section{Workload}

49073 new patients with cancer were reported to have been seen in 2008, $43 \%$ of the 115126 estimated new cases of cancer. ${ }^{10}$ An average of 270 new patients were reported to have been seen per FTE MO. 21954 new patients seen in 2008 (45\%) received at least one course of chemotherapy, with an average of 160 (ranging from 94 in South Australia to 198 in NSW) new patients receiving chemotherapy per FTE MO. The national chemotherapy utilisation rate was $19 \%$.

\section{Future supply}

There were 85 medical oncology advanced training positions identified, of which $74(87 \%)$ were filled. There were 91 medical oncology advanced trainees registered with the RACP in 2009. The number of firstyear trainees increased from 11 to 39 between 2005 and 2009. Numbers of registered trainees exceed training positions identified because some trainees work in positions outside medical oncology (eg, palliative care). There were 32 OTPs nationally, with the highest number in Queensland. Thirty-two FTE MOs (14\%) were expected to retire between 2009 and 2014 (about six FTE MOs per year).

\section{Current and projected demand}

For an optimal workload of 150 new patients/FTE MO/year, the demand for FTE MOs was 391 in 2009 and 432 in 2014 (Box 3). For an optimal workload of 180 new patients, the demand was 326 in 2009 and 361 in 2014. The highest demand (over optimal workload) for FTE MOs was in NSW.

\section{Current and projected shortfall of medical oncologists}

For the current supply of 234 FTE MOs, the shortfall of FTE MOs (over optimal workload) was 92 to 157 in 2009, and 84 to 156 in 2014 (Box 3). The highest absolute shortfalls were in NSW and Queensland (Box 4).

\section{Discussion}

We identified a current shortage of MOs in Australia, expected to persist in the future. A conservative estimate of the current supply, demand and shortfall of MOs was 234, 326 and 92 FTE respectively (at a workload of 150 new patients/FTE MO/year). Shortfalls of MOs were found in all states and territories and in metropolitan and rural centres.

MOs in Australia in 2008 had a high clinical workload compared with international benchmarks. The average number of new patients per FTE MO of 270 is well above Canadian recommendations of 160 to $175^{1}$ and the suggested Australian benchmark of 150 new patients per year. ${ }^{13}$ Reduction of this clinical workload requires training more than double the estimated shortage of FTE MOs, given that the average FTE per MO was 0.5 (Box 2). The increasing diversification of MOs into non-clinical roles will only increase the demand on clinical responsibilities should the shortage not be addressed.

The national chemotherapy utilisation rate was surprisingly low, and well below the evidence-based Australian standard of $51 \% .^{12}$ This is of concern because it implies that some patients who may benefit from chemotherapy are not receiving it. Possible explanations for a low chemotherapy utilisation rate include suboptimal referral rates of patients with cancer, patients referred with advanced rather than early stage cancer, and low prescribing rates of chemotherapy to new patients with cancer. We suspect that we have underestimated the chemotherapy utilisation rate, because only one-third of centres (representing about $60 \%$ of the total national $\mathrm{MO}$ workload) reported the number of new patients who received chemotherapy. However, even correcting for the underestimate, it is unlikely that chemotherapy utilisation in Australia approximates expected standards.

The number of trainees was greater than the number MOs expected to retire. This suggests that the supply of MOs should be able to meet the increased demand over the next 5 years, assuming full integration of the trainees into the medical oncology workforce. However, allowing for part-time work practices, overseas 
placements and maternity and other leave, the increasing supply of trainees does not allow for a substantial increase in the capacity of the medical oncology workforce to address the current shortage. Supplementation of the workforce by OTPs is welcome, but is limited by their uncertain supply.

Although not directly comparable, our findings are similar to the results of the most recent study of the oncology workforce in the US, ${ }^{7}$ and studies of the medical workforce in other oncology specialties such as radiation oncology $^{14}$ and palliative care. ${ }^{15}$ The US study found that demand for MOs is expected to rise by $48 \%$ between 2005 and 2020, but supply will only rise $14 \%$, translating into a shortfall of 2550 to 4080 oncologists (about one-quarter to one-third of the 2005 supply).

Our study has several limitations. The response rate of $81 \%$ was acceptable, but may not have been high enough to generalise the results to all MOs and practices in Australia. Lead clinicians, rather than individual MOs, were surveyed to maximise the response rate, but this was at the cost of detailed knowledge about workplace patterns of individual MOs. Only the clinical workload of MOs relating to chemotherapy was included, so the results may have underestimated the true workload of MOs in Australia, which also includes other systemic therapies such as hormonal therapy. Our study highlighted the lack of basic data collection at some oncology practices. Some responses were estimated rather than counted, and many centres were una- ble to provide any data about workload. This reduced the accuracy of the results and is likely to have underestimated the workload relating to new patients.

Despite these limitations, we provide a snapshot of the current medical oncology workforce in Australia, and an estimate of the current and future workforce shortages. Addressing the shortage needs a multilevel approach aimed at increasing the supply of MOs by increasing recruitment, training and participation rates, improving clinical practice efficiency, and the introduction of innovative methods of service delivery through involvement of other health professionals and use of models of shared care.

Tailored national strategies will be necessary to ensure an adequate medical oncology workforce in the future, and ongoing monitoring will be needed to guide and promote the strategies.

Acknowledgements: We thank the Medical Oncology Group of Australia for support.

Competing interests: No relevant disclosures.

Received 28 Mar 2011, accepted 5 Sep 2011.

1 Systemic Therapy Task Force. STTF Report. Ontario: Cancer Care Ontario, 2000. https:// www.cancercare.on.ca/common/pages/ UserFile.aspx?fileld=14436 (accessed Nov 2011).

2 Erikson C, Salsberg E, Forte G, et al. Future supply and demand for oncologists: challenges to assuring access to oncology services. J Oncol Pract 2007; 3: 79-86.

3 Hortobagyi GN; American Society of Clinical Oncology. A shortage of oncologists? The American Society of Clinical Oncology workforce study.J Clin Oncol 2007; 25: 1468-1469.

4 Warren JL, Mariotto AB, Meekins A, et al. Current and future utilization of services from medical oncologists.J Clin Oncol 2008; 26: 3242-3247.

5 Barrett J. Building for the future. Clin Oncol (R Coll Radiol) 2009; 21: 573-574.
6 Australian Medical Workforce Advisory Committee. The specialist medical and haematological oncology workforce in Australia: supply, requirements and projections, 2001-2011. Sydney: AMWAC, 2001. http://www.ahwo. gov.au/publications.asp (accessed Nov 2011).

7 Association of American Medical Colleges Center for Workforce Studies. Forecasting the supply of and demand for oncologists: a report to the American Society of Clinical Oncology. Alexandria, Va: ASCO, 2007. http://www.asco. org/ASCO/Downloads/Cancer\%20Research/ Oncology\%20Workforce\%20Report\%20FINAL. pdf (accessed Nov 2011).

8 National Cancer Institute, Division of Cancer Control and Population Sciences, Surveillance Research Program. SEER*Rx Interactive Antineoplastic Drugs Database, version 1.5.0. Bethesda, Md: NCl, 2010. http://www.seer. cancer.gov/tools/seerrx/ (accessed Nov 2011).

9 Australian Institute of Health and Welfare. Rural, Remote and Metropolitan Area (RRMA) classification. Canberra: AlHW, 2011. http://www. aihw.gov.au/rural-health-rrma-classification/ (accessed Dec 2011).

10 Australian Institute of Health and Welfare, Australasian Association of Cancer Registries. Cancer in Australia 2010: an overview. Canberra: AlHW, 2010. (AlHW Cat. No. CAN 56; Cancer Series No. 60.) http://www.aihw.gov.au/ publication-detail/?id=6442472459 (accessed Dec 2011).

11 Australian Bureau of Statistics. Australian demographic statistics, Jun 2009. Canberra: ABS, 2009. http://www.abs.gov.au/AUSSTATS/ abs@.nsf/allprimarymainfeatures/EB76EA379A 44E842CA2576F0001C70C9?opendocument (accessed Dec 2011).

12 Ng WL, Jacob S, Delaney G, et al. Optimal chemotherapy utilization rate in cancer care: setting an evidence-based benchmark for quality improvement. J Clin Oncol 2010; 28 (15 Suppl): abstract 6099.

13 Barton M, Gabriel GS, Shafiq J. Overview of cance treatment services in Western Australia July 2008. Perth: Cancer Council Western Australia, 2008. http://www.cancerwa.asn.au/resources/ Overview_of_cancer_treatment_services_in Western_Australia.pdf (accessed Dec 2011).

14 Morgan G, Wigg D, Childs J. Projected requirements for radiation oncologists and trainees in Australia and New Zealand to 2007. Australas Radiol 2000; 44: 88-97.

15 Chiarella M, Duffield C. Workforce issues in palliative and end-of-life care. J Hosp Palliat Nurs 2007; 9: 334-341. 